Ärztliche Erfahrung beschränkt sich nicht auf medizinisches Fachwissen.

\section{Im Goldenen Zeitalter stehengeblieben}

An einem Vormittag saß ich mit einem 89-jährigen, rüstigen Herrn in der Sprechstunde. Eigentlich sollte der gering ausgeprägte Diabetes thematisiert werden. Das Gespräch bekam allerdings sehr schnell eine unerwartete Wende, da der Patient von einem immer weiter fortschreitenden Gewichtsverlust berichtete. Ob etwas Böses dahinterstecke, wollte er wissen.

Das Problem war uns aus der Vergangenheit bereits bekannt. Zum Ausschluss konsumierender Erkrankungen hatte ich schon mehrere Untersuchungen veranlasst, u. a. eine Computertomografie des Thorax und Abdomens, da trotz des fortgeschritten Alters ein Diagnostikwunsch bestanden hatte. Glücklicherweise hatte keine der Untersuchungen einen malignen Befund erge- ben, und wir beide hatten uns zunächst damit zufrieden gegeben.

Aber nun verlor er weiter an Gewicht, sodass wir an dem Punkt waren, uns grundsätzlich entscheiden zu müssen, ob wir weitere Diagnostik betreiben oder den Gewichtsverlust tolerieren sollten. Mitten in diese Überlegungen platzte der ältere Herr mit der Frage: „Frau Doktor, was soll ich eigentlich mit der Grammophonplatte machen?" Einen Moment war ich völlig baff. Dann fiel der Groschen: Er meinte damit die CD aus der radiologischen Abteilung.

Welch großen Technikwandel dieser Herr in seinem Leben schon miterlebt hatte! Ob er weitere Untersuchungen durchführen lassen wollte, ließen wir an diesem Tag offen.

Claudia Krite-Anthes, Springe

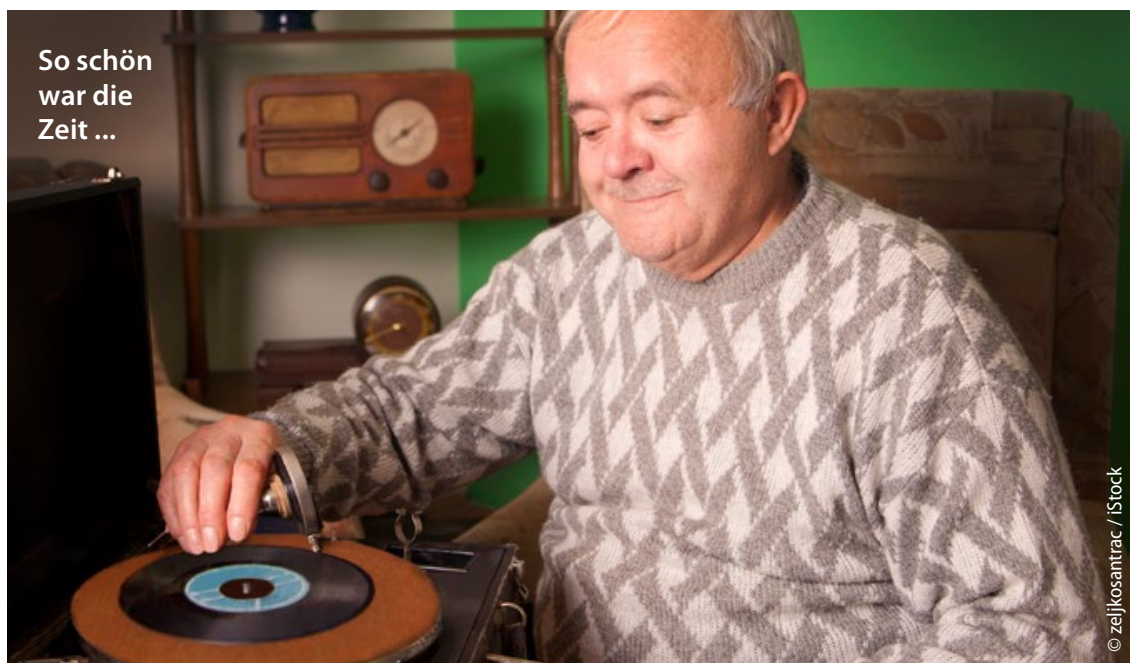

\section{Warum drängt mich Frau Doktor zum Toilettengang?}

Eine nur arabisch sprechende Asylbewerberin kam erstmals in mein Sprechzimmer. In ihrer Begleitung war ein Mann, der in der gleichen Einrichtung lebte und als Dolmetscher mitgeschickt worden war. Die Frau war bemüht, sich mit Gesten und einzelnen Wörtern verständlich zu machen. Um ihr die offensichtliche Peinlichkeit zu ersparen, bat ich den Mann, zur Untersuchung vor die Tür zu gehen.

\section{Der Dolmetscher interveniert}

Am Ende wollte ich zur genaueren Abklärung noch den Urin untersuchen. Deshalb bat ich den Dolmetscher wieder herein und erklärte ihm und der Frau, dass sie nun zur Toilette müsse. Das Wort Toilette schien sie zu verstehen, sah aber ansonsten etwas ratlos zweifelnd aus. Mit einem Schwall arabischer Wörter konnte der Mann ihre Skepsis zerstreuen. Folgsam verließ sie das Sprechzimmer in Richtung Toilette.

Leider konnten wir den Urin nicht untersuchen, da bei ihr nur angekommen war, dass sie auf die Toilette gehen sollte - wo sie ihre Blase entleerte ohne den Urin aufzufangen. Damit erklärte sich im Nachhinein der zweifelnde Gesichtsausdruck. Ich nahm mir vor, trotz aller Umständlichkeit und Zeitnot in solchen Fällen lieber noch mal nachfragen zu lassen, was unklar ist.

Andrea Linsel, Lüneburg 